\title{
The new Brazilian Society of Urology
}

\section{A nova Sociedade Brasileira de Urologia}

\author{
ARChimedes NardozZa JUNIOR ${ }^{1 *}$ \\ ${ }^{1}$ President of the Sociedade Brasileira de Urologia (SBU) (2016-2017) \\ *Correspondence: \\ Address: Rua Bambina, 153, Botafogo \\ Rio de Janeiro, RJ - Brazi \\ Postal code: 22251-050 \\ http://portaldaurologia.org.br/fale-conosco/
}

http://dx.doi.org/10.1590/1806-9282.63.08.663

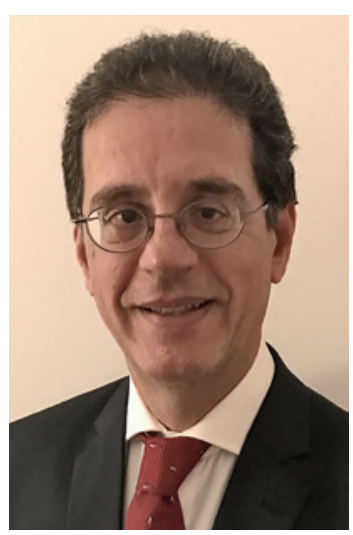

The Brazilian Society of Urology (SBU) has undergone a restructuring process in recent years. If we currently have a financially balanced and structured organization both from an administrative and a scientific point of view, a lot of that is due to the colleagues that preceded me.

The former directors have promoted reformulations and have, with their effort and dedication, transformed the SBU into an organization that is recognized as an example of efficiency and work.

We know that the Brazilian political and economic situation is not favorable. We have gone and are still going through difficult times, especially from an economic point of view. We are experiencing the result of the actions of a government that institutes disastrous economic and social policies, besides supporting campaigns and projects to defame the medical class in general.

If we have arrived at this moment with reasons to celebrate, it is thanks to the proper planning and hard work of this entire senior management. Efficient teamwork has enabled us to overcome this difficult time.

We cannot lose sight of the idea that taking care of a person's life is one of the noblest activities and we, those who help prepare professionals who will perform such a noble office, have twice the responsibility.

We have a strong continuing education branch and we will continue to strengthen this important initiative. The performance in medical residences and professional valorization are priorities of this administration.

We improve the present without losing sight of the future. The extremely efficient Teaching and Training
Commission (TTC) is responsible for the accreditation and supervision of the residency centers. We are launching software to monitor all residency centers, seeking to homogenize the training of the resident doctor.

Also thinking about improving our professionals' performance, we are working with the Specialist Title Commission in order to value our TiSBU more and more.

We have created a Professional Valuation Committee with representation in Brasília and in several organizations such as the Brazilian Medical Association (AMB, in the Portuguese acronym), Federal Board of Medicine (CFM, in the Portuguese acronym), National Regulatory Agency for Private Health Insurance and Plans (ANS, in the Portuguese acronym), Brazilian Health Surveillance Agency (Anvisa, in the Portuguese acronym) and others.

We have gained international recognition by strengthening ties with important organizations such as the American Urology Association (AUA), the European Association of Urology (EAU) and the American Confederation of Urology (CAU, in the Spanish acronym).

With these actions, in addition to developing projects that benefit urologists, we are regaining our organization's credibility.

This work has the purpose of showing some of our scientific activity and sharing achievements with you, as a great team of professionals that are part of the Brazilian Society of Urology.

We appreciate the efforts of all those involved in this project. 